\title{
Toxoplasma infection in sheep from south of Iran monitored by serological and molecular methods; risk assessment to meat consumers
}

\author{
Belal Armand ${ }^{1}$, Kavous Solhjoo ${ }^{1,2}$, Manoochehr Shabani-Kordshooli², Mohammad Hasan Davami ${ }^{1}$ and Mehdi Sadeghi ${ }^{3}$ \\ 1. Department of Parasitology and Mycology, Jahrom University of Medical Sciences, Jahrom, Iran; \\ 2. Department of Parasitic Disease, Zoonoses Research Center, Jahrom University of Medical Sciences, Jahrom, Iran; \\ 3. Department of Biology, Islamic Azad University, Shiraz Branch, Shiraz, Iran. \\ Corresponding author: Kavous Solhjoo, e-mail: solhjouk@yahoo.com, \\ BA: armand_pl91@yahoo.com, MSK: shabani.bi@gmail.com, MHD: davamimh@gmail.com, \\ MS: sadeghi.mehdi419@gmail.com \\ Received: 18-05-2016, Accepted: 11-07-2016, Published online: 13-08-2016
}

doi: 10.14202/vetworld.2016.850-855 How to cite this article: Armand B, Solhjoo K, Shabani-Kordshooli M, Davami MH, Sadeghi M (2016) Toxoplasma infection in sheep from south of Iran monitored by serological and molecular methods; risk assessment to meat consumers, Veterinary World, 9(8): 850-855.

\begin{abstract}
Aim: Toxoplasma gondii has a clinical and veterinary importance as it is known to cause congenital disease and abortion both in humans and livestock. Since the contaminated lamb is one of the sources of human infection, this study was performed to determine the prevalence of $T$. gondii in sheep in south of Iran.

Materials and Methods: Sera and tissue samples (diaphragm and heart) were collected from 370 sheep from slaughterhouse of Jahrom. The samples were taken from both sexes and from 6 to 60 months age. Specific immunoglobulin G antibodies to $T$. gondii were examined with enzyme-linked immunosorbent assay, and $B 1$ gene nested-polymerase chain reaction detection was done to survey the tissue samples.

Results: The total prevalence of Toxoplasma infection among sheep was found to be $35.94 \%$ and $34.32 \%$ based on serological and molecular method, respectively. According to serologic and molecular findings, the females were more positive than males for Toxoplasma; maximum frequency of positive samples was observed in 24-36 months and the positive samples had been collected more in spring than in summer, but no statistical correlation was observed between prevalence rate and the age and sex of animals or season of sampling.

Conclusion: T. gondii is widely distributed in sheep in Jahrom with a rate comparable with other parts of Iran and the world. It suggested a widespread exposure of sheep in this region to $T$. gondii. Thus, consumption of undercooked or raw meat presents the transmission risk of the parasite and this might be considered as an important public health problem, mainly for high-risk groups such as the pregnant and the immunodeficient.
\end{abstract}

Keywords: $B 1$ gene, enzyme-linked immunosorbent assay, meat consumers, nested-polymerase chain reaction, sheep, Toxoplasma gondii.

\section{Introduction}

Zoonotic diseases are one of the major public health problems in many countries. One of these diseases is toxoplasmosis. Toxoplasmosis is a widespread zoonosis caused by Toxoplasma gondii, a ubiquitous coccidian parasite of felines, man and many wild or domestic warm-blooded animals [1]. Herbivores acquire infection generally by the ingestion of oocysts, shed by infected cats, in water or contaminated food, and humans become infected post-natally by ingesting tissue cysts from undercooked meat [2].

The parasite has clinical and veterinary importance as it is known to cause congenital disease and abortion both in humans and livestock [3]. Acquired toxoplasmosis is normally asymptomatic or has mild

Copyright: Armand, et al. Open Access. This article is distributed under the terms of the Creative Commons Attribution 4.0 International License (http://creativecommons.org/licenses/ by/4.0/), which permits unrestricted use, distribution, and reproduction in any medium, provided you give appropriate credit to the original author(s) and the source, provide a link to the Creative Commons license, and indicate if changes were made. The Creative Commons Public Domain Dedication waiver (http:// creativecommons.org/publicdomain/zero/1.0/) applies to the data made available in this article, unless otherwise stated. non-specific symptoms in immunocompetent persons, while in immunocompromised individuals might be life threatening [4].

It is well known that meat from persistently infected animals is one of the most important potential sources of human toxoplasmosis [5]. Hence, it is necessary to investigate the prevalence of $T$. gondii infection among meat producing animals. Sheep are important to the economy of many countries because they are a source of nutrition for humans. Epidemiological investigations have revealed a significant correlation between human toxoplasmosis and the consumption of raw or undercooked meat or its products [2].

T. gondii in sheep is a source of infection for humans and carnivorous animals [6]. Various serological and molecular tests have been widely used by researchers in epidemiological studies on animal and human toxoplasmosis worldwide [7-12]. The prevalence of toxoplasmosis was reported in different livestock such as sheep in different parts of Iran which is varied between $13.8 \%$ and $35 \%$ for sheep [13-15]. In addition, a seroprevalence rate of $51.8 \%$ has been reported for all parts of Iran [16]. The seroprevalence 
rate of Toxoplasma infection in Fars province, by focusing on Shiraz city, has been reported to be $26.5 \%$ in sheep [17]. Moreover, tissue cysts were observed in $38 \%$ of tissue samples of sheep by molecular methods in southwest of Iran [18].

There is little information concerning toxoplasmosis rate in sheep in southern parts of Iran. Furthermore, sheep breeding is significantly common in this area, and since the contaminated lamb is one of the sources of human infection, this study was performed to determine the prevalence of $T$. gondii in sheep using both serological and molecular methods in the south of Fars. This survey provides an accurate picture of the risk of exposure to T. gondii in a common source of meat products.

\section{Materials and Methods}

\section{Ethical approval}

The experiment on animals including all procedures of this study was approved by the local Ethical Committee in Jahrom University of Medical Sciences.

\section{Study area and sampling}

The animals were chosen from the main slaughterhouse of Jahrom district, south of Fars province, where animals gathered from different regions of the district, between Aprils and June 2013. Jahrom is situated in a zone with $1050 \mathrm{~m}$ height from sea level where the temperature can become high in summer and a mild winter. Within the study area, 370 sheep blood samples were randomly collected from slaughtered sheep. In addition, the tissue samples were taken from diaphragm and heart of all animals for molecular examination. The animals had been born and raised in the region and were intended for human consumption. Demographic information such as sex, age, and breeding area of samples was recorded. The age of animals was ranging from 6 to 60 months.

\section{Serologic examination}

Sera of samples were separated and stored at $-20^{\circ} \mathrm{C}$ until assayed. Specific immunoglobulin G antibodies to $T$. gondii were examined with enzyme-linked immune assay using $T$. gondii Human Kit of DIA.PRO Italian Company and Abcam Company sheep serum conjugate. Negative control was obtained from a newborn sheep. After the study protocol had been approved by the Local Ethical Committee, the sheep was infected by two steps injection of live tachyzoites intramuscular and subdermal for obtaining positive control sample.

The optical density (OD) was read with a spectrophotometer (MULTISKAN MCC/340 P VERSION
2.33) at $492 \mathrm{~nm}$. The absorbance average of each serum tested in duplicate was divided by the cut off (mean absorbance of negative serum samples plus three standard deviations) to determine the reactivity index (RI). Serum with RI 1 was considered positive.

\section{Molecular examination}

For extraction of DNA, the tissue samples were homogenized and DNA was extracted using phenol-chloroform and Proteinase K. The extracted DNA was stored at $-20^{\circ} \mathrm{C}$ until use. Two polymerase chain reaction (PCR) primer pairs of the $B 1$ gene were used has been showed on Table-1. These primers amplifying a $193 \mathrm{bp}$ bond at the initial phase and a $96 \mathrm{bp}$ fragment at the second round of nested-PCR.

The first amplification was performed in $20 \mu 1$ of PCR-PreMix (Bioneer Company, South Korea) reaction mixture and $1 \mu \mathrm{l}$ of each primer and $2.5 \mu \mathrm{l}$ of extracted DNA (5-50 nanogram). The PCR condition was $93^{\circ} \mathrm{C}$ for $10 \mathrm{~min}$, followed by 40 cycles of $93^{\circ} \mathrm{C}$ for $10 \mathrm{~s}$ of denaturation, $57^{\circ} \mathrm{C}$ for $10 \mathrm{~s}$ of annealing and $72^{\circ} \mathrm{C}$ for $30 \mathrm{~s}$ of extension, and the last extension step at $72^{\circ} \mathrm{C}$ for $5 \mathrm{~min}$.

The second amplification was carried out in the same volumes as the first reaction with the $1 \mu$ of the first round product as template and $1 \mu 1$ of each inner primer. The PCR condition was $93^{\circ} \mathrm{C}$ for $10 \mathrm{~min}$, followed by 40 cycles of $93^{\circ} \mathrm{C}$ for $10 \mathrm{~s}$ of denaturation, $62.5^{\circ} \mathrm{C}$ for $10 \mathrm{~s}$ of annealing and $72^{\circ} \mathrm{C}$ for $15 \mathrm{~s}$ of extension, and the last extension step at $72^{\circ} \mathrm{C}$ for 5 min.

Each amplification run contained two negative controls (doubly distilled water and negative control of DNA extraction) and one positive control (DNA extracted from RH T. gondii tachyzoite). The PCR products were analyzed by electrophoresis in a $2 \%$ agarose gel stained with ethidium bromide $(0.5 \mathrm{mg} / \mathrm{ml})$. The DNA fragments were visualized under ultraviolet illumination.

\section{Statistical analysis}

The Chi-square test was used to clarify whether sex, age, or season of sampling was associated with the prevalence rate of $T$. gondii in sheep. The results were analyzed by SPSS software (version 13) and a $\mathrm{p}<0.05$ was considered as significant positive correlation.

\section{Results}

The number of 370 sheep (279 female and 91 male) were examined using both serological and molecular methods. The sampling was done during two seasons of spring (193 sheep) and summer

Table-1: Position and sequences of the primer pairs used in nested-PCR.

\begin{tabular}{llr}
\hline Oligonucleotide primer & Sequence & Sequence position \\
\hline Outer primer (sense strand) & 5'-GGAACTGCATCCGTTCATGAG-3' & $694-714$ \\
Outer primer (nonsense strand) & 5'-TCTTAAAGCGTTCGTGGTC-3' $^{\prime}$ & $887-868$ \\
Inner primer (sense strand) & 5'-TGCATAGGTTGCAGTCACTG-3' $^{\prime}$ & $757-776$ \\
Inner primer (nonsense strand) & 5'-GGCGACCAATCTGCGAATACACC-3' $^{\prime}$ & $853-831$ \\
\hline
\end{tabular}

PCR: Polymerase chain reaction

Veterinary World, EISSN: 2231-0916 
(177 sheep). The animals were categorized in five age groups including 0-12 months (122), 12-24 months (70), 24-36 months (125), 36-48 months (34), and 48-60 months (19).

\section{Serological findings}

In this study, the samples with higher than 170 OD were considered positive. Anti-Toxoplasma antibodies were detected in sera of 133 out of $370(35.94 \%)$ animals. Considering the sex of animals, however the females (100 cases) were more seropositive than males (33 cases) for Toxoplasma, but the differences were not statistically significant $(\mathrm{p}=0.942)$. Moreover, the maximum and minimum frequency of positive samples were observed in 24-36 months (42.40\%) and 48-60 months $(31.58 \%)$ age groups, respectively, however no significant correlation was found between age and seropositivity to toxoplasmosis $(\mathrm{p}=0.470)$. In addition, 76 positive samples had been taken in spring and 57 in summer, but statistical analysis was indicated no correlation between season and the seropositivity $(\mathrm{p}=0.151)$. Serological findings are shown in Table-2 in detail.

\section{Molecular findings}

A nested-PCR assay was done for tissue (heart and diaphragm) samples taken from 370 sheep to amplify the $B 1$ gene. In general, 127 cases (34.32\%) showed a $193 \mathrm{bp}$ bond at initial step and a $96 \mathrm{bp}$ bond at the second round of nested-PCR assay (Figures-1 and 2). All the positive samples had been identified positive based on serological results. The statistical difference between the prevalence rates of Toxoplasma infection among females (96 cases) and males (31 cases) was not significant $(\mathrm{p}=0.886)$. Furthermore, no positive correlation was found between the age of animals and the rate of infection, in which the highest and lowest prevalence rate were observed in 3 years old age group and 1 year old age group, respectively $(p=0.055)$. Although 82 cases of positive samples had been collected in spring and 45 of them had been taken in summer, there was no positive relation observed between the rate of prevalence and season of sampling $(p=0.138)$. Molecular findings are shown in Table- 2 in detail.

\section{Discussion}

Nowadays, toxoplasmosis is considered as one of the most important food-borne diseases. Humans are getting the disease by consuming infected meat of livestock including sheep [19]. The results of this study showed that $35.94 \%$ of sheep have anti $T$. gondii antibody in their sera. In addition, $34.32 \%$ of animals' tissue contains $T$. gondii tissue cyst. Toxoplasmosis prevalence rate in the various zones of the world is variable, with ranging from $0 \%$ to $100 \%$ in different countries [20,21]. The differences observed could be due to diverse husbandry practices, lifestyles of the residents, traditions and the climatic variations from one region to another, which are known as essential elements in epidemiological investigations [22].

Our result is one of the highest rates which have been reported so far in different parts of Iran. Our findings were significantly more than those who reported in Kerman 3.3\% seropositivity in sheep [23]. This could be due to the differences of weather in the two areas. Kerman is a desert zone, while Jahrom with

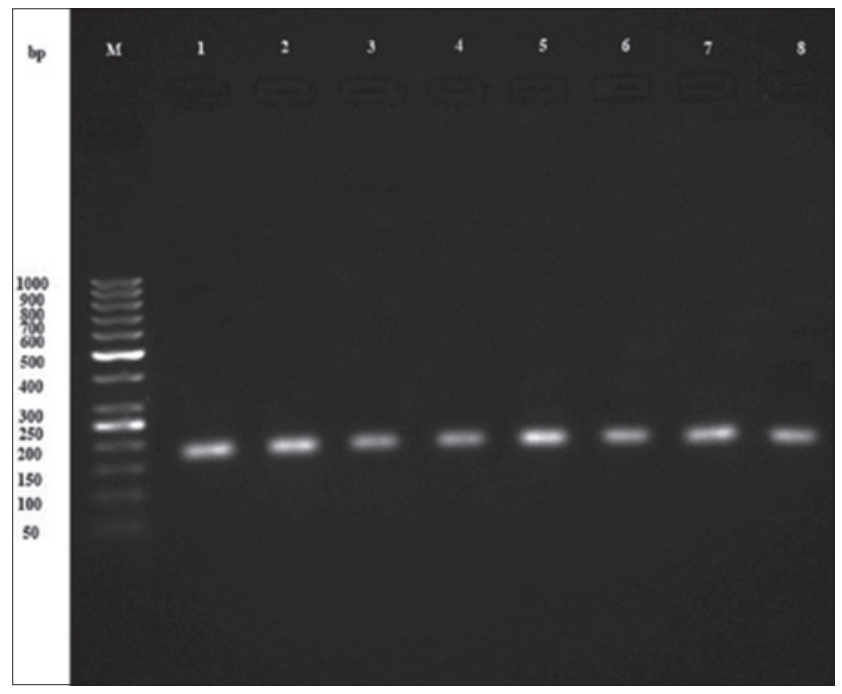

Figure-1: Electrophoresis result from primary step product of $\mathrm{B} 1$ gene nested-polymerase chain reaction products: M-100 bp marker, 1 - Positive control, 2-9: 193 bp bond of positive samples.

Table-2: Distribution of T. gondii infection in sheep based on serological and molecular results in correlation to sex, age group and season of sampling.

\begin{tabular}{lccc}
\hline Category & Number of animal examined & Number of ELISA positive (\%) & Number of nested-PCR positive (\%) \\
\hline $\begin{array}{l}\text { Season } \\
\text { Spring }\end{array}$ & 193 & $76(39.37)$ & $82(42.48)$ \\
Summer & 177 & $57(32.20)$ & $45(25.42)$ \\
Sex & 91 & $33(36.26)$ & $31(34.06)$ \\
Male & 279 & $100(35.84)$ & $96(34.40)$ \\
Female & 122 & $39(31.96)$ & $25(20.49)$ \\
Age group & 70 & $23(32.85)$ & $25(35.71)$ \\
$0-12$ & 125 & $53(42.40)$ & $57(45.60)$ \\
$12-24$ & 34 & $12(35.29)$ & $13(38.23)$ \\
$24-36$ & 19 & $6(31.58)$ & $7(36.84)$ \\
$36-48$ & 370 & $133(35.94)$ & $127(34.32)$ \\
$48-60$ & & & \\
Total & & & \\
\hline
\end{tabular}

T. gondii: Toxoplasma gondii, ELISA: Enzyme-linked immunosorbent assay, PCR: Polymerase chain reaction 


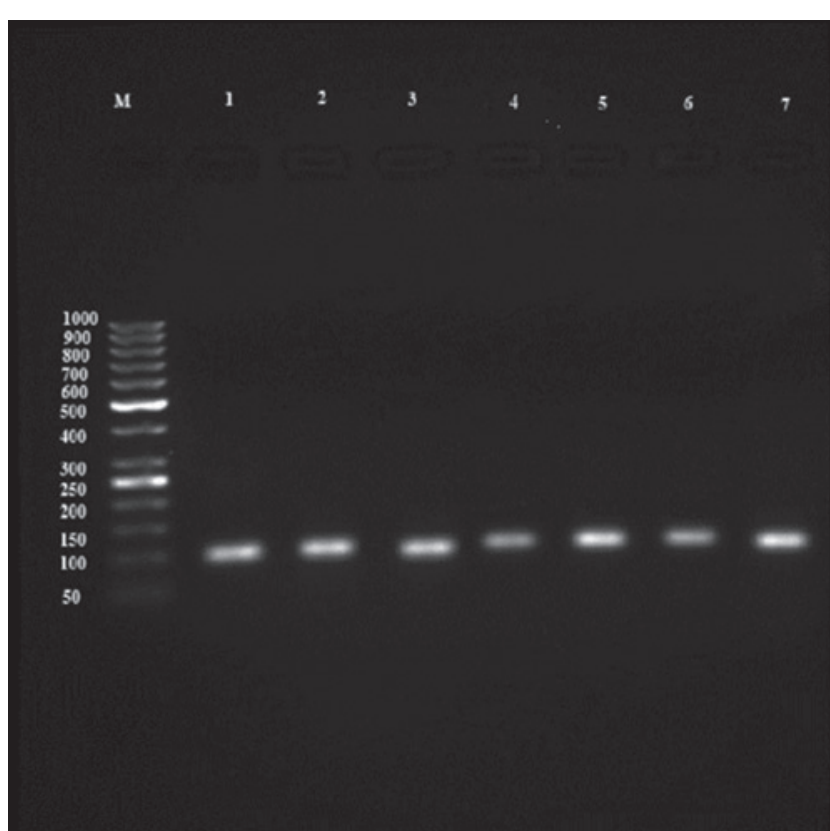

Figure-2: Electrophoresis result from secondary step product of $\mathrm{B} 1$ gene nested- Polymerase chain reaction: M-50 bp marker, 1- Positive control, 2-9: 96 bp bond of positive samples.

the vast citrus gardens looks more like a forest zone rather than a poor average annual rainfall area. In other aspect, cats and other felids play an important role in preserving and spreading of $T$. gondii in hosts such as livestock (e.g., sheep) because they are considered as the major source of the oocysts that contaminate the environment and after sporulation become infectious to man and animals [22]. Humidity and temperate condition favor the oocyst survival. To that effect, Fayer has indicated that the toxoplasmosis prevalence rate is elevated in humid and hot zones compared to dry regions and this gap is more probably due to the high viability of the oocysts in these environments [24].

In addition, it seems that the prevalence of $T$. gondii in sheep in the Jahrom district was slightly more than other parts of Iran such as Uroomye [25], ShahreKord [26], and Kurdistan [27] provinces, in the west and the mountainous part of Iran. In the mentioned regions, there were reports of the seropositivity of $21.1 \%, 29.1 \%$, and $21.74 \%$, respectively. Moreover, the average seroprevalence in Iran which was reported by Hashemi [28] about $24.5 \%$ is distinctly lower than our finding in this area. In comparison with other parts of Fars province, again our results showed a little difference, in which Asgari observed that $29.5 \%$ of sheep in northern part of Fars province hold anti-Toxoplasma antibody in the sera [29].

More interestingly, Sharifi reported 35\% sheep toxoplasmosis in three different regions, north of Iran, which is the most humid and forest part of the country. That was clearly similar to the findings of the present study. Sharifi, also, observed that seropositivity was higher in the western parts of the province where animals had been exposed to an environment contaminated with greater numbers of $T$. gondii oocysts, as a result of differences in the levels of humidity in these three areas [14]. Other studies across the world have confirmed this fact. In this regard, van der Puije in his study has indicated that the sheep toxoplasmosis varies from $20 \%$ in a dry region to $39 \%$ in forest areas [30]. It is worth mentioning that our findings were distinctly less than Greece, a Mediterranean country, where $48.6 \%$ of sheep were categorized seropositive [31]. Other studies in Ghana [30] and Portugal [32] which showed the same seroprevalence range as our study, around $33.2 \%$ and $33.6 \%$ infection, respectively.

To the best of this study, all the samples were subjected to a molecular survey to clarify the existence of parasite in the animals' tissue. The major purpose of this step was to determine whether T. gondii was present as a contaminant of human foodstuffs, and if so, the level of contamination present. Our findings show a high rate of toxoplasmosis infection in sheep tissues. Detecting this high level of contaminant in a small part of animal tissue $(5 \mathrm{~g})$ poses an alarming public health risk because it means that considerable numbers of farm animals currently contributing to the food chain of people carry $T$. gondii.

Our finding demonstrates the presence of $T$. gondii DNA within the samples, regardless of the viability of parasites which might initiate a human infection. However, it seems highly probable that a significant portion of the parasites observed in the present study would have been viable. Because, it is well proved that $T$. gondii tissue cysts are considerably strong and remaining viable for weeks at temperatures of $1-4^{\circ} \mathrm{C}$, and temperatures above $67^{\circ} \mathrm{C}$ or below $-12^{\circ} \mathrm{C}$ are needed to see a significant loss of viability $[33,34]$.

In other aspects, consuming the barbequed meat (kebab) and the processed meat products such as sausages have been dramatically increased in the recent years; which it clearly represents a significant risk of infection.

The results of this study showed that 33 out of 91 samples of male and 100 out of 279 samples of female animals were seropositive, but there was no statistical correlation between gender of sheep and the rate of seropositivity. This was in contrary to those who found a significant correlation between ewes and lambs [35]; whereas it was similar to the studies done in Iran and other parts of the world [26,29,31]. Some studies indicated a connection between the age of animals and the rate of Toxoplasma infection [11,14]; however, such connection was not observed in the current study like Asgari who did not find a statistical correlation in this kind [29]. In general, the prevalence of $T$. gondii varies with the methods of testing and cutoff values. It seems that the sensitivity and specificity of different tests are different that they might have some effects on results [36].

\section{Conclusion}

Regarding the foregone discussion, T. gondii is widely distributed in sheep in this region with a 
rate comparable with other parts of Iran and world. Obviously, the consumption of their undercooked or raw meat presents a risk of transmission of the parasite. This might be considered as an important public health problem, mainly for high-risk groups such as the pregnant and the immunodeficient. Likewise, other meats from other kinds of animals are currently used in Jahrom. It seems highly important to identify the other probable sources of infection to have a better vision to the role of meat diet in human infection with T. gondii and also to define the zoonotic aspect of this parasite.

\section{Authors' Contributions}

BA and KS have designed the concept and supervised the plan of work and also have prepared the manuscript. MS and MSK have contributed in sample collection, administrative, technical, and material support. KS and MHD have analyzed and interpreted the data. All authors have read and approved the final manuscript.

\section{Acknowledgment}

The authors would like to thank the personnel of Jahrom main slaughterhouse for their kind assistance. This study was financially (grant number: 1389/08/19-3) supported by Zoonosis Research Center of Jahrom University of Medical Sciences, Iran.

\section{Competing Interests}

The authors declare that they have no competing interests.

\section{References}

1. Bowman, D.D., Hendrix, C.M., Lindsay, D.S. and Barr, S.C. (2008) Feline Clinical Parasitology. John Wiley \& Sons, Chichester, UK.

2. Webster, J.P. (2010) Review of Toxoplasmosis of Animals and Humans. (Second Edition). by Dubey, J.P. Parasit. Vectors., 2010;3:112.

3. Bossi, P. and Bricaire, F. (2004) Severe acute disseminated toxoplasmosis. Lancet, 364(9434): 579.

4. Pereira-Chioccola, V.L., Vidal, J.E. and Su, C. (2009) Toxoplasma gondii infection and cerebral toxoplasmosis in HIV-infected patients. Future Microbiol., 4(10): 1363-1379.

5. Lundén, A. and Uggla, A. (1992) Infectivity of Toxoplasma gondii in mutton following curing, smoking, freezing or microwave cooking. Int. J. Food Microbiol., 15(3): 357-363.

6. Dubey, J.P. (2009) Toxoplasmosis in sheep-the last 20 years. Vet. Parasitol., 163(1): 1-14.

7. Matsuo, K., Kamai, R., Uetsu, H., Goto, H., Takashima, Y. and Nagamune, K. (2014) Seroprevalence of Toxoplasma gondii infection in cattle, horses, pigs and chickens in Japan. Parasitol. Int., 63(4): 638-639.

8. Hill, D.E. and Dubey, J.P. (2013) Toxoplasma gondii prevalence in farm animals in the United States. Int. J. Parasitol., 43(2): 107-113.

9. Dehkordi, F.S., Haghighi Borujeni, M.R., Rahimi, E. and Abdizadeh, R. (2013) Detection of Toxoplasma gondii in raw caprine, ovine, buffalo, bovine, and camel milk using cell cultivation, cat bioassay, capture ELISA, and PCR methods in Iran. Pathog. Dis., 10(2): 120-125.

10. Asgari, Q., Sarnevesht, J., Kalantari, M., Sadat, S.J.A., Motazedian, M.H. and Sarkari, B. (2011) Molecular survey of toxoplasma infection in sheep and goat from Fars province, Southern Iran. Trop. Anim. Health Prod., 43(2): 389-392.

11. Habibi, G.R., Imani, A.R., Gholami, M.R., Hablolvarid, M.H., Behroozikhah, A.M., Lotfi, M. and Bozorgi, S. (2012) Detection and identification of Toxoplasma gondii type one infection in sheep aborted fetuses in Qazvin Province of Iran. J. Parasitol., 7(3): 64-72.

12. Sharif, M., Daryani, A., Ebrahimnejad, Z., Gholami, S., Ahmadpour, E., Borhani, S. and Lamsechi, N. (2016) Seroprevalence of anti-toxoplasma IgG and IgM among individuals who were referred to medical laboratories in Mazandaran Province, Northern Iran. J. Infect. Public Health, 9(1): 75-80.

13. Navidpour, S. and Hoghooghi-Rad, N. (1998) Seroprevalence of anti - Toxoplasma gondii antibodies in buffaloes in Khoozestan Province, Iran. Vet. Parasitol., 77(2): 191-194.

14. Sharif, M., Gholami, S.H., Ziaei, H., Daryani, A., Laktarashi, B., Ziapour, S.P. and Vahedi, M. (2007) Seroprevalence of Toxoplasma gondii in cattle, sheep and goats slaughtered for food in Mazandaran Province, Iran, during 2005. Vet. J., 174(2): 422-424.

15. Ghazaei, C. (2006) Serological survey of antibodies to Toxoplasma gondii. Afr. J. Health Sci., 12(3): 114-117.

16. Assmar, M., Amirkhani, A., Piazak, N., Hovanesian, A., Kooloobandi, A. and Etessami, R. (1996) Toxoplasmosis in Iran. Results of a seroepidemiological study. Bull. Soc. Pathol. Exot., 90(1): 19-21.

17. Asgari, Q., Moazzeni, M., Mohajeri, F.A., Kalantari, M., Zarifi, M., Ghalebi, S.R. and Mehrabani, D. (2007) Seroprevalence of Toxoplasma gondii among caprines in Fars province, Southern Iran. J. Vet. Parasitol., 21(2): $153-155$.

18. Azizi, H., Shiran, B., Boroujeni, A.B. and Jafari, M. (2014) Molecular survey of Toxoplasma gondii in sheep, cattle and meat products in Chaharmahal va Bakhtiari Province, Southwest of Iran. Iran. J. Parasitol., 9(3): 429-434.

19. Santos, S.L., de Souza Costa, K., Gondim, L.Q., da Silva, M.S.A., Uzêda, R.S., Abe-Sandes, K. and Gondim, L.F.P. (2010) Investigation of Neospora caninum, Hammondia sp. and Toxoplasma gondii in tissues from slaughtered beef cattle in Bahia, Brazil. Parasitol. Res., 106(2): 457-461.

20. Olivier, A., Herbert, B., Sava, B., Pierre, C., John, D.C. and Aline, D.K. (2007) Surveillance and monitoring of toxoplasma in humans, food and animals: A scientific opinion of the panel on biological hazards. EFSA. J., 583: 1-64.

21. Tenter, A.M., Heckeroth, A.R., and Weiss, L.M. (2000) Toxoplasma gondii: From animals to humans. Int. J. Parasitol., 30(12): 1217-1258.

22. Elmore, S.A., Jones, J.L., Conrad, P.A., Patton, S., Lindsay, D.S. and Dubey, J.P. (2010) Toxoplasma gondii: Epidemiology, feline clinical aspects, and prevention. Trends. Parasitol., 26(4): 190-196.

23. Derakhshan, M. and Mousavi, M. (2014) Serological survey of antibodies to Toxoplasma gondii in cats, goats, and sheep in Kerman, Iran. Comp. Clin. Path., 23(2): 267-268.

24. Fayer, R. (1981) Toxoplasmosis update and public health implications. Can. Vet. J., 22(11): 344-352.

25. Raeghi, S., Akaberi, A. and Sedeghi, S. (2011) Seroprevalence of Toxoplasma gondii in sheep, cattle and horses in Urmia North-West of Iran. Iran. J. Parasitol., 6(4): 90-94.

26. Bonyadian, M., Hematzade, F. and Manuchehri, K. (2007) Seroprevalence of antibodies to Toxoplasma gondii in sheep in center of Iran. Pak. J. Biol. Sci., 10(18): 3228-3230.

27. Khezri, M., Mohammadian, B., Esmailnia, K. and Khezri, O. (2012) Toxoplasmosis in sheep from Kurdistan Province, Iran. Afr. J. Microbiol. Res., 6(18): 3989-3992.

28. Hashemi-Fesharki, R. (1996) Seroprevalence of Toxoplasma gondii in cattle, sheep and goats in Iran. Vet. Parasitol., 61(1): 1-3. 
29. Asgari, Q., Sarkari, B., Amerinia, M., Panahi, S., Mohammadpour, I. and Sarvestani, A.S. (2013) Toxoplasma infection in farm animals: A seroepidemiological survey in Fars province, South of Iran. Jundishapur. J. Microbiol., 6(3): 269-272.

30. Van der Puije, W.N.A., Bosompem, K.M., Canacoo, E.A., Wastling, J.M. and Akanmori, B.D. (2000) The prevalence of anti - Toxoplasma gondii antibodies in Ghanaian sheep and goats. Acta Trop., 76(1): 21-26.

31. Tzanidakis, N., Maksimov, P., Conraths, F.J., Kiossis, E., Brozos, C., Sotiraki, S. and Schares, G. (2012) Toxoplasma gondii in sheep and goats: Seroprevalence and potential risk factors under dairy husbandry practices. Vet. Parasitol., 190(3): 340-348.

32. Lopes, A.P., Dubey, J.P., Neto, F., Rodrigues, A., Martins, T., Rodrigues, M. and Cardoso, L. (2013) Seroprevalence of Toxoplasma gondii infection in cattle, sheep, goats and pigs from the North of Portugal for human consumption. Vet.
Parasitol., 193(1): 266-269.

33. Kotula, A.W., Dubey, J.P., Sharar, A.K., Andrews, C.D., Shen, S.K. and Lindsay, D.S. (1991) Effect of freezing on infectivity of Toxoplasma gondii tissue cysts in pork. J. Food Prot., 54(9): 687-690.

34. Dubey, J.P., Kotula, A.W., Sharar, A., Andrews, C.D. and Lindsay, D.S. (1990) Effect of high temperature on infectivity of Toxoplasma gondii tissue cysts in pork. The J. Parasitol., 76(2): 201-204.

35. Dumètre, A., Ajzenberg, D., Rozette, L., Mercier, A. and Dardé, M.L. (2006) Toxoplasma gondii infection in sheep from Haute-Vienne, France: Seroprevalence and isolate genotyping by microsatellite analysis. Vet. Parasitol., 142(3): 376-379.

36. Shaapan, R.M., El-Nawawi, F.A. and Tawfik, M.A.A. (2008) Sensitivity and specificity of various serological tests for the detection of Toxoplasma gondii infection in naturally infected sheep. Vet. Parasitol., 153(3): 359-362.

$* * * * * * * *$ 